\title{
Tunable mesoporous Bragg reflectors based on block-copolymer self-assembly
}

\author{
Stefan Guldin, Mathias Kolle, Morgan Stefik, Richard Langford, Dominik Eder, Ulrich Wiesner, and Ullrich
}

\section{Steiner}

Distributed Bragg reflectors (DBRs) consist of periodically alternating layers of high and low refractive index materials, also known as one-dimensional photonic crystals. Interference of light reflected at the interfaces of the dielectric layers leads to strong reflection in a well defined wavelength range resulting in pronounced structural colouration. The spectral response can be finely tuned by varying the refractive index, the thickness, and the number of the alternating layers. ${ }^{1}$ Simple configurations are realized by sequential coating of thin solid films of alternating refractive index. Direct access to a 1D dielectric lattice via solution processing has been achieved by the self-assembly of block copolymers into a lamellar morphology. ${ }^{2,3}$

A interesting recent area of research is the development of mesoporous DBRs (MDBRs) which access new fields of applications due to their porosity on the sub-optical length scale. MDBRs are promising as sensing materials. The adsorption and desorption of gas phase molecules in the pores leads to reversible changes in the refractive index and thereby in the photonic properties of the stack. ${ }^{4-7}$ Bonifacio et al. introduced the concept of a MDBR-based "photonic nose". 8 Other applications include the use of MDBRs as environmentally responsive resonance cavities ${ }^{10,11}$ and their coupling to mesoporous surface layers. ${ }^{12}$ MDBRs also have great potential in optoelectronic devices. When infiltrated with light emitting polymers, MDBRs have exhibited distributed feedback lasing. ${ }^{13}$ Efficiency enhancements have been demonstrated by integrating a MDBR into a dye-sensitized solar cell. ${ }^{14}$ Recently, the coupling of plasmonic particles to MDBR-based resonant cavities has been shown. ${ }^{15}$

Typically, the refractive index contrast is realized by the alternating deposition of mesoporous layers of $\mathrm{TiO}_{2}$ and $\mathrm{SiO}_{2}$. This concept was first introduced by Ozin and coworkers, who manufactured a $\mathrm{TiO}_{2} / \mathrm{SiO}_{2}$ stack with ordered mesoporous morphologies, following a block copolymer directed sol-gel route. ${ }^{4}$ While the MDBRs exhibited an interconnected pore network, the stack fabrication was extremely time consuming with fabrication times of 4 days or more for each consecutive layer. ${ }^{4,5}$ A less complex alternative is the sequential deposition of nanoparticle-based solutions to form mesoporous films. The group of Cohen introduced this concept for a homopolymer mediated nanoparticle approach following numerous dip-coating cycles. ${ }^{9}$ Miguez et al. subsequently presented

S. Guldin, Dr. M. Kolle, Dr. R. Langford, Prof. U. Steiner

Department of Physics, University of Cambridge,

J. J. Thomson Avenue, Cambridge CB3 OHE, UK

e.-mail: u.steiner@phy.cam.ac.uk

Dr. D. Eder

Department of Materials Science and Metallurgy, University of Cambridge, Pembroke Street, Cambridge CB2 3QZ, UK

Dr. M. Stefik, Prof. U. Wiesner

Department of Materials Science \& Engineering, Cornell University,

Ithaca, New York 14853, USA

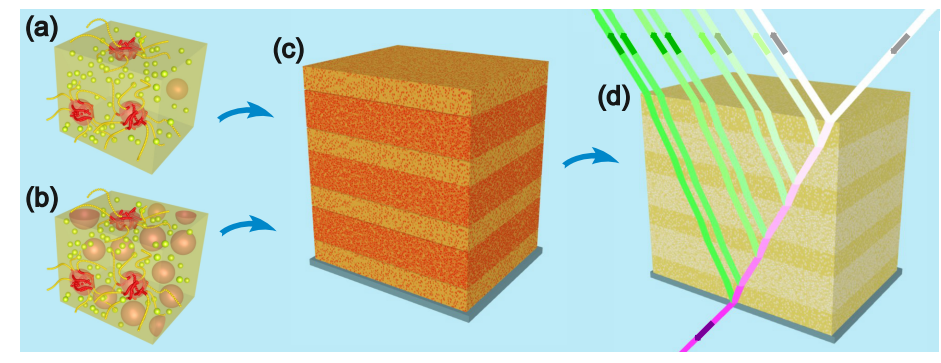

Figure 1. Schematic of MDBR fabrication. Two solutions of $\mathrm{TiO}_{2}$ sol and $\mathrm{PI}-b$-PEO copolymer were mixed in weight ratios of 3:1 ( $\left.\mathrm{T}_{3: 1}\right)$ and 1:2 $\left(\mathrm{T}_{1: 2}\right)$. Spin-coating of films from these solution leads to $\mathrm{TiO}_{2}$ polymer hybrid networks with differing titania content illustrated in (a) and (b) for the 3:1 and 1:2 ratios, respectively. MDBR stacks were built-up by direct spin-coating of alternating solutions. After each layer deposition the stack was subject to a $30 \mathrm{~min}$ annealing protocol. The final stack (c) was calcined at $500{ }^{\circ} \mathrm{C}$ for $2 \mathrm{~h}$ to remove the polymer and crystallize the $\mathrm{TiO}_{2}$ (c). The photonic effect of the MDBR arises from the alternating sequence of high and low porosity layers (d).

a straightforward procedure of directly spincoating nanoparticle containing solutions to form films of defined thicknesses. ${ }^{16}$ The optical properties of these films are a function of the nanoparticle material and the layer porosity, ${ }^{17}$ which can be tuned via the particle size. Along these lines, the Miguez group has also built a MDBR from a single material by the alternating deposition of suspensions of different $\mathrm{TiO}_{2}$ particle sizes. ${ }^{18}$ The nanoparticle random-close packing however restricts the achievable porosity, requiring low porosity in one of the alternating layers to realize a sufficient refractive index contrast. The resulting low pore connectivity may limit applications which rely on the porosity of the entire stack.

Here, we present a fast and versatile fabrication route for MDBRs which relies on the self assembly of the block copolymer poly(isoprene- $b$-ethylene oxide) (PI- $b$-PEO) in combination with simple hydrolytic sol-gel chemistry. The use of this block copolymer system enables extended control of porosity and pore size in the resulting inorganic material and allows the fast and reliable assembly of a continuous network with well defined optical interfaces.

A schematic representation of the MDBR fabrication method is shown in Fig. 1. Two stock solutions containing $\mathrm{TiO}_{2}$ sol and PI- $b$-PEO copolymer in $3: 1$ and 1:2 weight ratios (referred to as " $\mathrm{T}_{3: 1}$ " and " $\mathrm{T}_{1: 2}$ ") were sequentially spin-cast to form a stack of alternating composition. After calcination at $500{ }^{\circ} \mathrm{C}$ to remove the polymer and crystallize the $\mathrm{TiO}_{2}$, a MDBR with layers of alternating high and low refractive indices is revealed. See Experimental Section for details.

The manufacture of thick porous films derived from a solgel-polymer composite is problematic because of the considerable shrinkage during the condensation reaction, polymer removal and titania crystallization, which typically leads to 

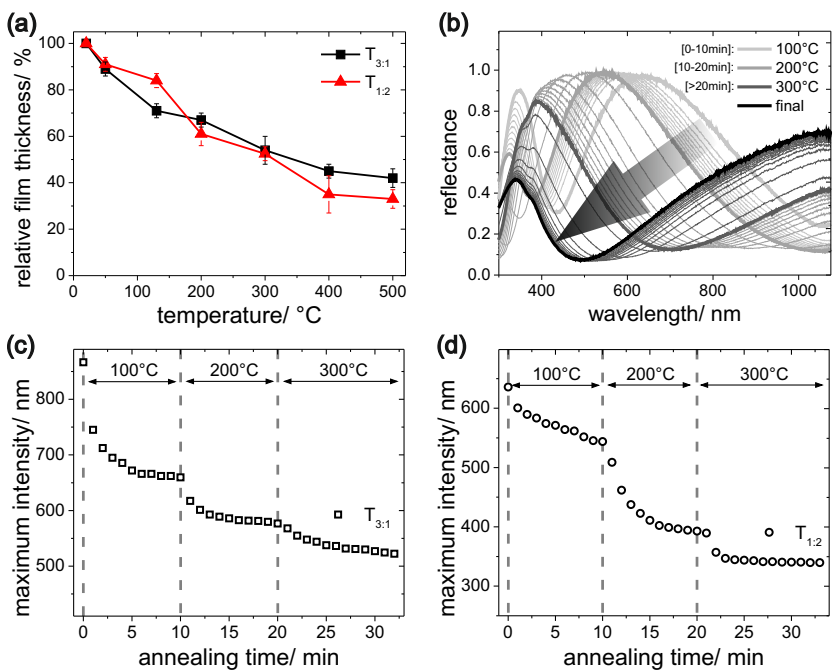

Figure 2. Temperature-dependent shrinkage of hybrid films (a) Relative shrinkage of hybrid films as a function of the processing temperature. (b) In-situ reflectance of hybrid $\mathrm{T}_{1: 2}$ films during consecutive annealing at $100^{\circ} \mathrm{C}$ (light grey), $200^{\circ} \mathrm{C}$ (grey) and $300^{\circ} \mathrm{C}$ (dark grey) for $10 \mathrm{~min}$ each. The spectra are for films on silicon wafers normalized by the reflectivity of a bare wafer. (c), (d) Corresponding plot of maximum reflectance intensity for $T_{3: 1}$ and $T_{1: 2}$, respectively. The change in reflectance suggests that film shrinkage is complete within the 10 min interval at each temperature.

crack formation and delamination. In order to maintain film integrity it is therefore necessary to anneal each layer after spincoating, following a carefully chosen temperature profile. Figure $2 \mathrm{a}$ shows the relative shrinkage of hybrid films as a function of the processing temperature. The films have been heat-treated for extended times (overnight) at each temperature to achieve equilibration. After condensation, calcination and crystallization, $\mathrm{T}_{3: 1}$ films shrunk to $\approx 42 \%$ of their initial thickness, while the more porous $\mathrm{T}_{1: 2}$ films contracted to $\approx 33 \%$. Substantiated by Thermogravimetric analysis (TGA) of equivalent bulk blends (see Supporting Information), we attribute most of the shrinkage to the condensation of hydrolyzed $\mathrm{Ti}(\mathrm{OH})_{4}$ to $\mathrm{TiO}_{2}$, which occurs at temperatures below $300{ }^{\circ} \mathrm{C}$. In our hybrid networks, a substantial fraction of organic matter is still present in the film at $300^{\circ} \mathrm{C}$. The sacrificial material plays a crucial role in the stack build-up. The pores of underlying films are protected and cannot clog up during sequential spin-coating, which leads to highly interconnected inorganic networks after a final calcination step. ${ }^{20}$ Cyclic annealing after each layer deposition has another beneficial effect: the condensation of the inorganic network prevents the partial dissolution of the layer when contacted by the solution for the next layer. This is essential for the formation of well defined interfaces, which are a requirement for a high optical quality of the MDBR.

The total processing time is an important parameter for technological feasibility of a manufacturing procedure. To optimize MDBR fabrication, we therefore directly monitored the film shrinkage process in situ. $\mathrm{T}_{3: 1}$ and $\mathrm{T}_{1: 2}$ were spincoated onto silicon wafers and the reflection spectra of individual layers were collected during annealing on a hot plate.
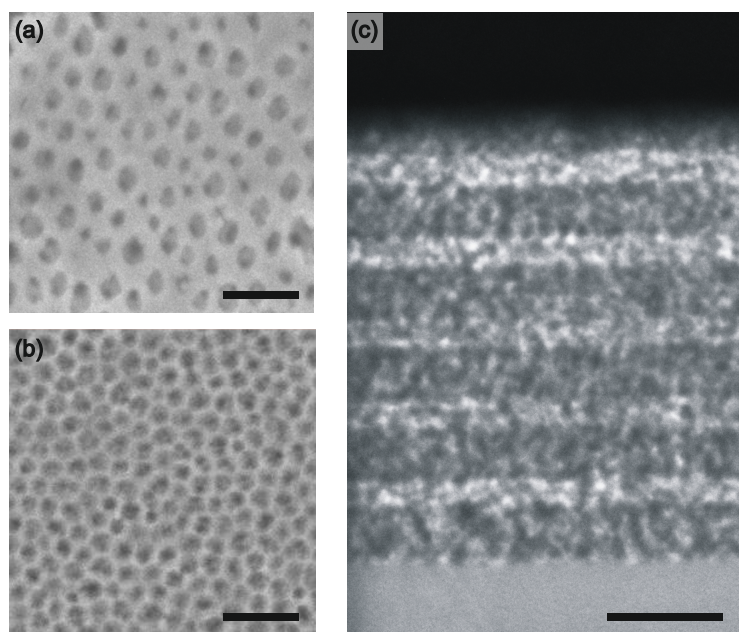

Figure 3. Electron microscopy images of the MDBR after calcination at $500{ }^{\circ} \mathrm{C}$.(a) SEM top view of a $\mathrm{T}_{3: 1}$ film with refractive index $n_{3: 1} \approx 1.69$. (b) SEM top view of a highly porous film $\mathrm{T}_{1: 2}$ film with $n_{1: 2} \approx 1.41$. (c) TEM cross-sectional view of a MDBR stack. The darker layers correspond to the high $\mathrm{TiO}_{2}$ content of $\mathrm{T}_{3: 1}$, the brighter low $\mathrm{TiO}_{2}$ layers are $\mathrm{T}_{1: 2}$. Scale bars are $200 \mathrm{~nm}$.

The results were used to establish a 30 minute annealing protocol consisting of three consecutive $10 \mathrm{~min}$ steps at $100^{\circ} \mathrm{C}$, $200^{\circ} \mathrm{C}$ and $300^{\circ} \mathrm{C}$. Figure $2 \mathrm{~b}$ shows reflection spectra of a $\mathrm{T}_{1: 2}$ film during the annealing protocol taken in one-minute intervals. The thinning of the films corresponds to a shift of the reflectance maxima and minima to smaller wavelengths. For clarity, the spectral position of the maximum reflectance is plotted in Fig. 2c,d as a function of time for $\mathrm{T}_{3: 1}$ and $\mathrm{T}_{1: 2}$, respectively. $\mathrm{T}_{3: 1}$ shrinkage (Fig. 2c) is significantly faster than for the lower inorganic loading of $\mathrm{T}_{1: 2}$ (Fig. 2b,d). In both cases, the results indicate that the shrinkage process is completed within the 10 min interval at each temperature.

Figure 3 shows electron microscopy images of MDBR layers and an entire stack after calcination at $500^{\circ} \mathrm{C}$. The top-view scanning electron microscopy (SEM) images in Fig. 3a and b clearly show the differing porosities of the high $\left(\mathrm{T}_{3: 1}\right)$ and low $\left(\mathrm{T}_{1: 2}\right)$ titania content, respectively. While the pore size of the two layers is comparable, the pore density differs significantly. The optical properties of individual layers were investigated by imaging ellipsometry. We determined the effective refractive indices of the layers to be $n_{3: 1} \approx 1.69$ and $n_{1: 2} \approx 1.41$ for $\mathrm{T}_{3: 1}$ and $\mathrm{T}_{1: 2}$, respectively. In fact, extending our method by carefully varying the inorganic to organic ratio, we are able to precisely adjust the refractive index to any value between 1.4 and 1.9. This range is well above previously reported approaches to tune the refractive index by porosity for MDBR manufacture. ${ }^{5,18}$ To visualize an entire MDBR stack, thin cross-sectional slices were prepared by focussed ion-beam milling. The two different MDBR layers are clearly discernible in the transmission electron microscopy (TEM) image of Fig. 3c. The darker layers correspond to a high electron density and therefore a high $\mathrm{TiO}_{2}$ content $\left(\mathrm{T}_{3: 1}\right)$, with the brighter layers stemming from $\mathrm{T}_{1: 2}$. The films have been sputter coated with platinum for the ion milling process. As a consequence, the top layer in this image has partially been infiltrated by the as black perceptible metal. 
Our MDBRs have a well-defined band gap that gives rise to a characteristic color appearance. This is visible in photographs of MDBRs in Fig. 4a-d. All stacks consist of five $\mathrm{T}_{3: 1}$ layers separated by four $\mathrm{T}_{1: 2}$ layers . In this series, the $\mathrm{T}_{3: 1}$ layer thickness was kept constant while the the thickness of the $\mathrm{T}_{1: 2}$ layer was varied. As a result the reflected MDBR color shifts from purple over blue and green to yellow. These images are a direct illustration that the presented method is capable to homogeneously stack nine layers while keeping a laterally highly uniform optical response.

The experimental reflection spectra in Fig. 4e are in line with the photographs. They indicate the ease, with which the optical response of the MDBR can be tuned over the whole visible spectrum, by varying the concentration of the $\mathrm{T}_{1: 2}$ solution. The traces in Fig. 4e correspond to stacks consisting of five $75 \mathrm{~nm}$-thick $\mathrm{T}_{3: 1}$ layers separated by four $\mathrm{T}_{1: 2}$ layers with thicknesses ranging from $78 \mathrm{~nm}$ to $202 \mathrm{~nm}$. The experimental reflectivity of Fig. $4 \mathrm{~g}$ is characteristic for a MDBR with an optical band gap centered at $\approx 630 \mathrm{~nm}$. Figure $4 \mathrm{~h}$ shows a model calculation following Rouard's technique. ${ }^{1}$ The modeling parameters are based on the thickness and refractive index of the individual layers, measured by ellipsometry. Experimental and calculated traces for 5, 9, and 13 layers in Fig. $4 \mathrm{~g}$ and $\mathrm{h}$ are very similar. This comparison illustrates the high optical quality of the MDBRs, even when all layers are built from the same material, thus the refractive index contrast is only generated by the alternating porosity of the building blocks. Our technique results in a high refractive index contrast and well-defined interfaces between the layers, surpassing previous single material approaches.

To confirm the pore interconnectivity across the entire stack and to demonstrate its suitability as a sensor, the porous MDBR was infiltrated by different liquids with refractive indices ranging from 1.33 to 1.55 . Fig. 4 f shows a shift of the Bragg peak to longer wavelengths, which is the result of a change in the refractive index contrast of the layers as the air in the pores is replaced by the higher refractive index liquids. These results are in good agreement with the calculated shift of the peak position, calculated by the symmetric Bruggeman effective medium approximation (Supplementary Figure S3), confirming the full accessibility of the entire pore network.

Compared to the nanoparticle route, polymer-directed sol-gel approaches to MDBRs have typically been timeconsuming and were limited in conductivity due to the lack of structural stability at high crystallization temperatures. The present approach can overcome these limitations. We were able to identify processing conditions which limit the fabrication time for each layer to $30 \mathrm{~min}$, reducing the overall manufacturing time for an entire MDBR to several hours. The main reason for this lies in the high Flory-Huggins interaction parameter of the isoprene-ethylene oxide couple, their low glass-transition temperatures, and the high molecular weight of the block-copolymer. Because of the stronger overall driving force for PI-PEO separation combined with their high mobility, PI- $b$-PEO self-assembly occurs orders of magnitudes faster compared to the widely used Pluronic polymers. ${ }^{21,22}$ Utilising PI- $b$-PEO for $\mathrm{TiO}_{2}$ synthesis, structural stability and fidelity during calcination can be maintained up
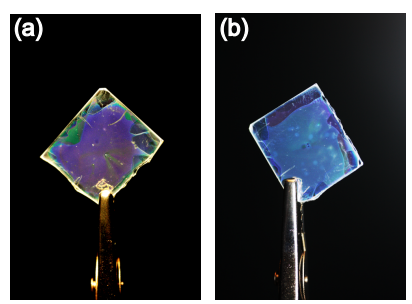

(e)
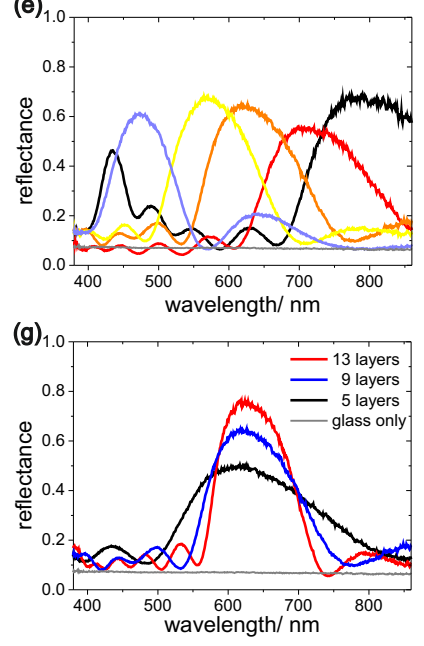

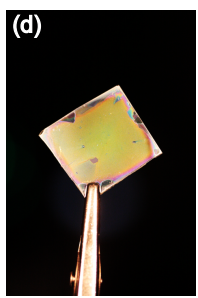

(f)
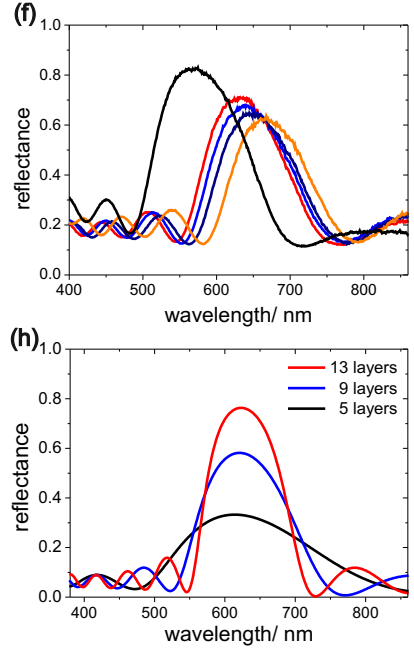

Figure 4. Optical properties of MDBRs. Exemplary MDBRs consisting of five $T_{3: 1}$ layers and four layers $T_{1: 2}$. The thickness of the $\mathrm{T}_{3: 1}$ layers was kept constant while the $\mathrm{T}_{1: 2}$ layers were varied in thickness to give rise to reflection colors of (a) purple over (b) blue to (c) green and (d) orange. (e) Experimental reflectance of stacks consisting of five layers with $d_{3: 1} \approx 75 \mathrm{~nm}$ and four layers of $d_{1: 2}$ ranging from $\approx 78 \mathrm{~nm}$ (reflection peak at $\approx 475 \mathrm{~nm}$ ) to $\approx 202 \mathrm{~nm}$ (peak at $\approx 800 \mathrm{~nm}$ ). (f) Optical response of a 9 layer MDBR stack in air (black) and after infiltration with $\mathrm{H}_{2} \mathrm{O}$ (red), 2-propanol (blue), chloroform (green), and 1,2-dichlorobenze (orange). (g), (h) Comparison of experimental and theoretical reflectance. The stacks consist of individual layers with $n_{3: 1}=1.69, d_{3: 1}=75 \mathrm{~nm}$ and $n_{1: 2}=1.41$, $d_{1: 2}=132 \mathrm{~nm}$, determined by ellipsometry. Calculated DBR reflectance are based on these parameters. Modelling was carried out using a Matlab algorithm based on Rouard's technique. ${ }^{1}$

to $700{ }^{\circ} \mathrm{C},{ }^{23}$ leading to highly crystalline networks. The large PI volume fraction $(76.9 \%)$ is the origin of the high porosity, yielding an inorganic material which is less susceptible to shrinkage and structural collapse. As a result it is possible to vary the polymer/inorganic weight ratio between from 1:2 to $3: 1$, yielding a refractive index difference of $\sim 0.3$. The PI$b$-PEO-based route offers a number of advantages for future MDBR design. As shown in Fig. 3a,b the manufacture process conserves the pore size, decoupling it from the layer refractive index. The pore density (and thereby the refractive index) can be set through the inorganic-to-organic mixing ratio, while the pore-size is determined by the PI molecular weight. In earlier studies pore sizes between 20 and $80 \mathrm{~nm}$ were obtained by adjusting the molecular weight of the hydrophobic

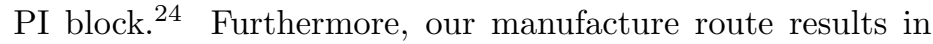
MDBRs consisting of a three-dimensional bicontinuous network with fully accessible pores. There is now an abundant range of sol-gel chemistry-based approaches which are compatible with block-copolymer assembly. ${ }^{25,26}$ It is therefore 
possible to extend the presented $\mathrm{TiO}_{2}$-based MDBRs to a wide range of ceramics and metal oxides.

Fully porous MDBRs consisting of a single material are promising for a wide range of applications. In sensing, adsorption-desorption properties and their correlated MDBR optical response depend on the pore size as well as chemical and structural nature of the pore walls, ${ }^{6}$ which can be individually controlled by the presented MDBR manufacture route. The variation of porosity should allow the optical detection of gas phase molecules as well as surface-binding molecules from solution. For integration into optoelectronic devices such as hybrid lasers or hybrid solar cells, MDBRs have to consist of a conducting network with full pore interconnectivity. We have recently demonstrated the excellent conductivity of similarly prepared $\mathrm{TiO}_{2}$ networks and showed the manufacture of dyesensitised solar cells based on this material. ${ }^{23}$ The MDBR stack of Fig. 3 is therefore an interesting candidate for the manufacture of a dye-sensitised solar cell with an integrated DBR.

In conclusion, we present a straight-forward route for MDBR manufacture which harnesses the self-assembly of the PI- $b$-PEO block-copolymer in combination simple hydrolytic sol-gel chemistry to generate optically uniform layers of well defined porosity. Varying the organic-inorganic content of the mixture enables the fine-control of the pore density (and thereby the refractive index), while the pore size can be tuned by the polymer molecular weight. The fast and reliable assembly of the components into a continuous network permits the direct manufacture of MDBR stacks with sharp interfaces. A 30 min annealing protocol per layer supports the MDBR build-up and prevents cracking of the films. The presented approach allows to control the pore size, porosity and material composition of the final stack, thereby presenting new opportunities for MDBR manufacture and integration into functional devices.

\section{Experimental Section}

Material fabrication: MDBRs were fabricated as follows. A titaniumcontaining sol was obtained by rapidly adding $\mathrm{HCl}(0.69 \mathrm{ml}, 37 \%$, BASF) to titanium ethoxide ( $1 \mathrm{ml}$, purum, Fluka) under vigorous stirring. Two stock solutions for high and low refractive index layers were then prepared separately. For $\mathrm{T}_{3: 1}, 1.31 \mathrm{ml}$ sol was mixed with $0.1 \mathrm{~g}$ of $a$ isoprene-ethylene oxide block-copolymer (PI-b-PEO) (molecular weight $\left.M_{\mathrm{n}}=34.4 \mathrm{~kg} \mathrm{~mol}^{-} 1,28 \mathrm{wt} \% \mathrm{PEO}\right)^{19}$ in tetrahydrofuran $\left(\mathrm{THF}, 7 \mathrm{ml}\right.$ ). The solution was then poured into a petri dish at $50^{\circ} \mathrm{C}$. Shortly after solvent evaporation, the dry material was redissolved in a mixture of $49 \mathrm{vol} \%$ toluene (apolar) and 51 vol\% 1-butanol (polar). For $\mathrm{T}_{1: 2}, 0.22 \mathrm{ml}$ sol was mixed with $0.1 \mathrm{~g}$ Pl- $b$-PEO in THF. After solvent evaporation at $50^{\circ} \mathrm{C}$, the dry material was in this case redissolved in a mixture of toluene $(73 \mathrm{vol} \%)$ and 1-butanol $(27 \mathrm{vol} \%)$. The concentrations of the hybrid solutions were adjusted to meet the calculated MDBR layer thickness requirements. For film deposition, solutions were spin coated at $2000 \mathrm{rpm}$ onto pre-cleaned glass substrates followed by annealing at $100^{\circ} \mathrm{C}, 200^{\circ} \mathrm{C}$ and $300^{\circ} \mathrm{C}$ for $10 \mathrm{~min}$ each. MDBR stacks were build-up by spin-coating $\mathrm{T}_{3: 1}$ and $\mathrm{T}_{1: 2}$ solutions in alternating order, each followed by the $30 \mathrm{~min}$ annealing protocol. Finally, the samples were calcined at $500^{\circ} \mathrm{C}$ ( 2 hours, heat ramp $5{ }^{\circ} \mathrm{C} \min ^{-} 1$ ) to remove the organic material, crystallize the $\mathrm{TiO}_{2}$ and reveal the MDBR.

Material characterisation: Scanning electron microscopy was carried out on a Leo Ultra 55 with a field emission source of $3 \mathrm{kV}$ acceleration voltage. Transmission electron microscopy was performed on a FEI Philips Tecnai 20 with $200 \mathrm{kV}$ acceleration voltage. For thermogravimetric analysis samples were characterised with a TA instruments Q500 in high resolution dynamic mode with a ramp of $\approx 2{ }^{\circ} \mathrm{C} \min ^{-} 1$. Spectroscopic reflection measurements were carried out on a Olympus BX51 microscope with $5 \times$ magnification and detected with a Ocean Optics QE 65000 spectrometer. Ellipsometric data were taken on a Nanofilm ep3se imaging ellipsometer and the instrument software was used ot analyze the data. For modelling of the MDBRs, Rouards technique was implemented in a MatLab algorithm. A transfer matrix algorithm coded in $\mathrm{C}^{++}$was used to verify the data.

\section{Acknowledgements}

This work was funded in part by the EPSRC (EP/F056702/1 and EP/ F065884/1), the Department of Energy (DE-FG02 87ER45298) through the Cornell Fuel Cell Institute (CFCl), the National Science Foundation (DMR-0605856), and the Cornell University KAUST Center for Research and Education. M.S. was supported by the Cornell Fuel Cell Institute and the Energy Materials Center at Cornell (EMC2), an Energy Frontier Research Center funded by the U.S. Department of Energy, Office of Science, Office of Basic Energy Sciences under Award Number DE-SC0001086. The authors thank Prof. Jeremy Baumberg and Dr. Silvia Vignolini for help with the optical characterization and useful discussions.

[1] O. S. Heavens, Optical properties of thin solid films, Dover Publications Inc., 2nd edition, 1992, ISBN 978-0486669243.

[2] A. Urbas, Y. Fink, and E. L. Thomas, Macromolecules, 1999, 32, 4748.

[3] J. Yoon, W. Lee, and E. L. Thomas, MRS Bulletin, 2005, 30, 721.

[4] S. Y. Choi, M. Mamak, G. V. Freymann, and N. Chopra, G. A. Ozin, Nano Lett., 2006, 6, 2456.

[5] M. C. Fuertes, F. J. Lopez-Alcaraz, M. C. Marchi, H. E. Troiani, V. Luca, H. Miguez, and G. J. d. A. Arturo Soler-Illia, Adv. Funct. Mater., 2007, 17, 1247.

[6] C. Fuertes, S. Colodrero, G. Lozano, A.R. Gonzalez-Elipe, D. Grosso, C. Boissiere, C. Sánchez, G. J. d. A. Arturo Soler-Illia, and H. Míguez, J. Phys. Chem. C 2008, 112, 3157.

[7] L. D. Bonifacio, B. V. Lotsch, D. P. Puzzo, F. Scotognella, and G. A. Ozin, Adv. Mater., 2009, 21, 1641.

[8] L. D. Bonifacio, D. P. Puzzo, S. Breslav, B. M. Willey, A. McGeer, and G. A. Ozin, Adv. Mater., 2010, 22, 1351.

[9] Z. Wu, D. Lee, S. Breslav, M. F. Rubner, and R. E. Cohen, Small, 2007, 3, 1445.

[10] O. Sánchez-Sobrado, M. E. Calvo, N. Núñez, M. Ocaña, G. Lozano, and H. Míguez, Nanoscale, 2010, 2, 936.

[11] O. Sánchez-Sobrado, G. Lozano, M. E. Calvo, A. SánchezIglesias, L. M. Liz-Marzán, H. Míguez, Adv. Mater., 2011, 23, 2108.

[12] N. Hidalgo, M. E. Calvo, H. Míguez, Small, 2010, 5, 2309.

[13] D. P. Puzzo, F. Scotognella, M. Zavelani-Rossi, M. Sebastian, A. J. Lough, I. Manners, G. Lanzani, R. Tubino, and G. A. Ozin, Nano Lett., 2009, 9, 4273.

[14] S. Colodrero, A. Mihi, L. Haggman, M. Ocaña, G. Boschloo, A. Hagfeldt, and H. Míguez, Adv. Mater., 2009, 21, 764.

[15] N. Hidalgo, M. E. Calvo, M. Bellino, G. J. Soler-Illia, H. Míguez, Adv. Funct. Mater., 2011, DOI: 10.1002/adfm.201002486.

[16] S. Colodrero, M. Ocaña, and H. Míguez, Langmuir, 2008, 24, 4430.

[17] N. J. Hutchinson, T. Coquil, A. Navid, and L. Pilon, Thin Solid Films, 2010, 518, 2141.

[18] M. E. Calvo, S. Colodrero, T. C. Rojas, J. A. Anta, M. Ocaña, and H. Míguez, Adv. Funct. Mater., 2008, 18, 2708. 
[19] J. Allgaier, A. Poppe, L. Willner, and D. Richter. Macromolecules, 1997, 30, 1582.

[20] S. Guldin, S. Hüttner, M. Kolle, M. E. Welland, P. MuellerBuschbaum, R. H. Friend, U. Steiner, and N. Tetreault, Nano Lett., 2010, 10, 2303.

[21] M. Templin, A. Franck, A. DuChesne, H. Leist, Y. Zhang, R. UIrich, V. Schadler, and U. Wiesner, Science, 1997, 278, 1795.

[22] G. Floudas, R. Ulrich, and U. Wiesner, J. Chem. Phys., 1999, $110,652$.

[23] S. Guldin, S. Hüttner, P. Tiwana, M. C. Orilall, B. Ülgüt, M. Stefik, P. Docampo, M. Kolle, G. Divitini, C. Ducati, S. A. T. Redfern, H. J. Snaith, U. Wiesner, D. Eder, and U. Steiner, Energy Environ. Sci., 2011, 4, 225.

[24] M. Nedelcu, J. Lee, E. J. W. Crossland, S. C. Warren, M. C. Orilall, S. Guldin, S. Hüttner, C. Ducati, D. Eder, U. Wiesner, U. Steiner, and H. J. Snaith, Soft Matter, 2009, 5, 134.

[25] P. Yang, D. Zhao, D. Margolese, B. Chmelka, and G. Stucky, Nature, 1998, 396, 152.

[26] C. Sánchez, C. Boissière, D. Grosso, C. Laberty, and L. Nicole, Chem. Mater., 2008, 20, 682. 


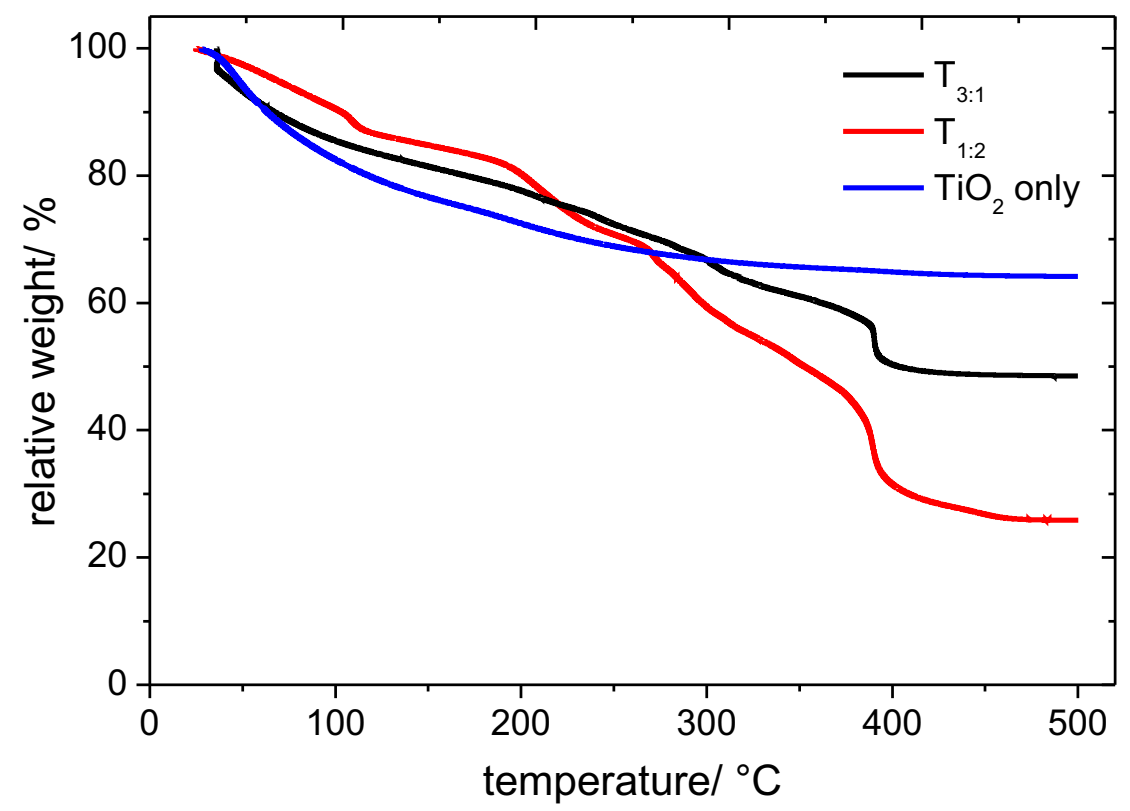

Supplementary Figure 1. Thermogravimetric analysis (TGA) of different material compositions. Samples were characterised with a Q500 Thermogravimetric Analyzer (TA Instruments) in high resolution dynamic mode. The weight loss, mostly due to the condensation of hydrolyzed $\mathrm{Ti}(\mathrm{OH})_{4}$ to $\mathrm{TiO}_{2}$ mirrors the development of film contraction up to $300^{\circ} \mathrm{C}$. The TGA results indicate that the condensation of the $\mathrm{TiO}_{2}$ network is complete at $300{ }^{\circ} \mathrm{C}$.

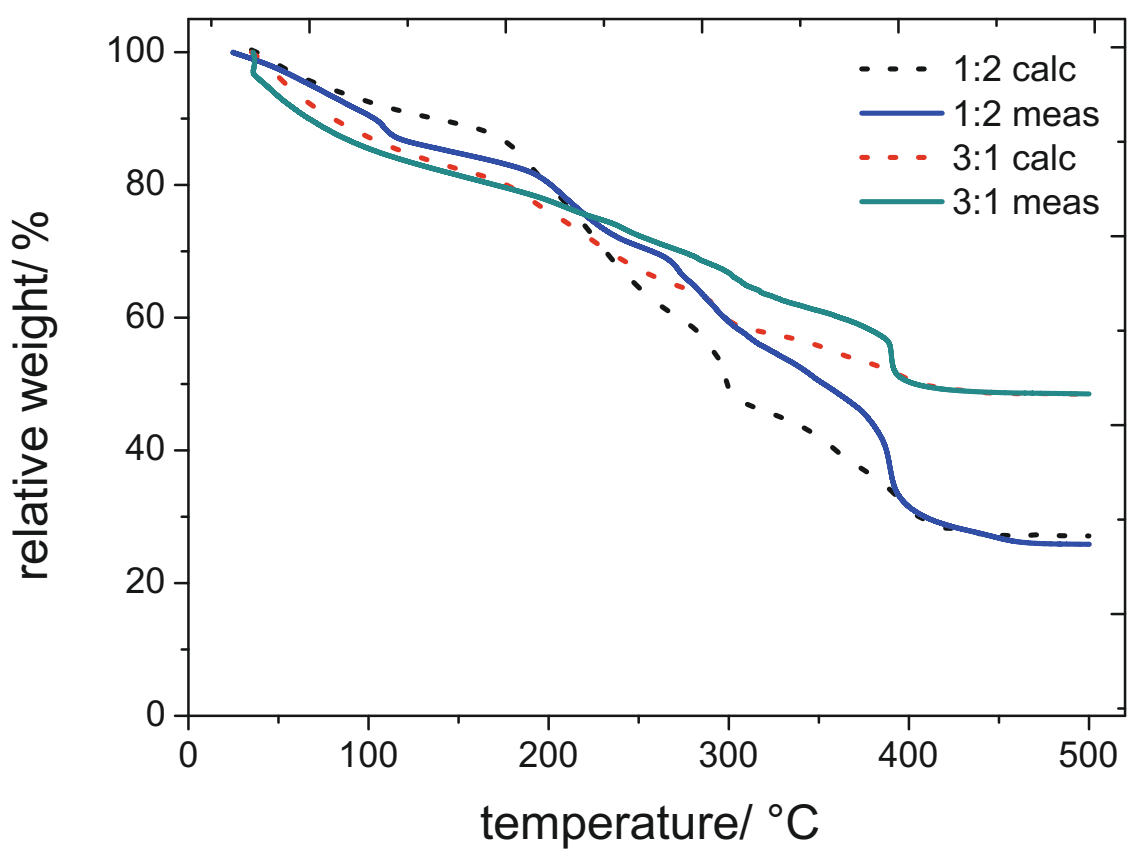

Supplementary Figure 2. Comparison of measured and calculated TGA results. Dotted lines are the weighed average of purely organic and inorganic traces. The weight loss in the hybrid samples is significantly delayed to higher temperatures, with a retardation in weight loss by $68^{\circ} \mathrm{C}$ and $75^{\circ} \mathrm{C}$ for $\mathrm{T}_{3: 1}$ and $\mathrm{T}_{1: 2}$, respectively. 


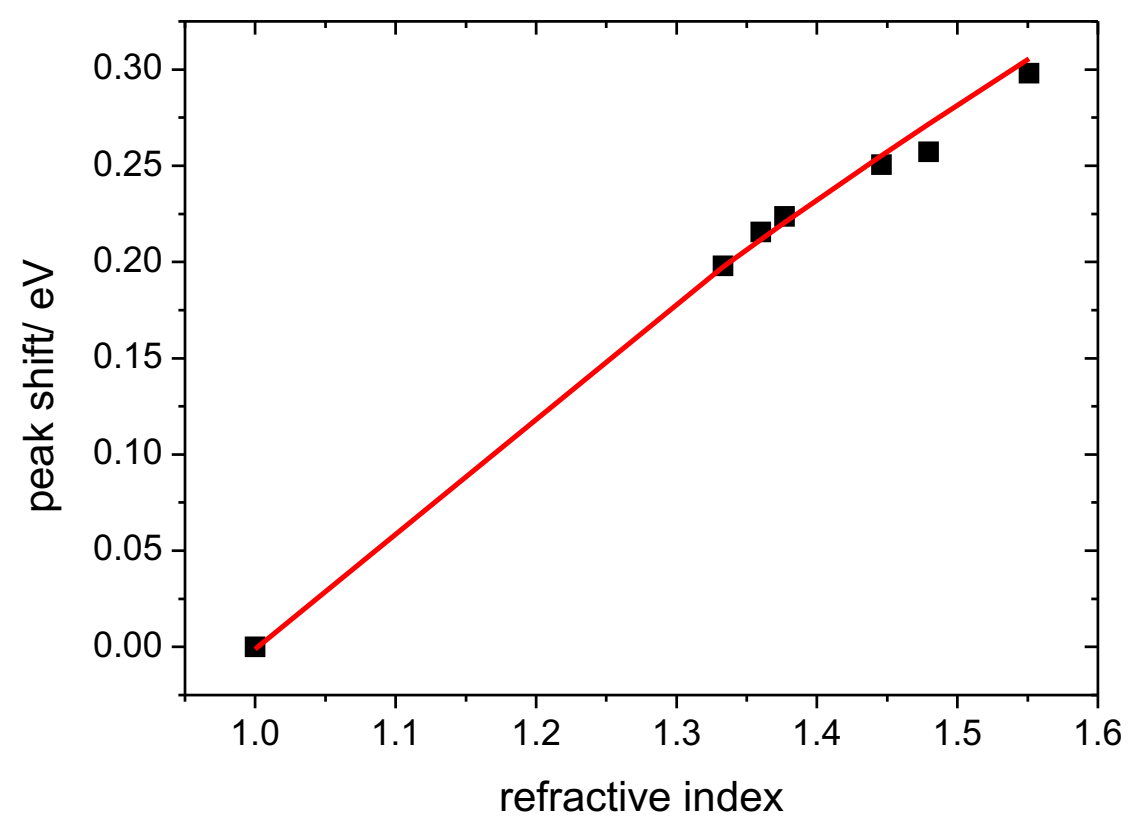

Supplementary Figure 3. Shift of Bragg peak position as a function of the refractive index of liquids infiltrated into the MDBR pores. A MDBR consisting of 5 layers $\mathrm{T}_{3: 1}(d=75 \mathrm{~nm})$ and 4 layers $\mathrm{T}_{1: 2}(d=75 \mathrm{~nm})$ was used for this study. The position of the Bragg peak was measured at $579 \mathrm{~nm}$ before infiltrating with $\mathrm{H}_{2} \mathrm{O}(n=1.333)$, ethanol $(n=1.360)$, 2-propanol $(n=1.377)$, chloroform $(n=1.4458)$, dimethyl sulfoxide $(n=1.4793)$, and 1,2-dichlorobenzene $(n=1.5509)$. The red line corresponds to the calculated shift of the Bragg peak calculated by the symmetric Bruggeman effective medium approximation. This prediction confirms ellipsometry results of uninfiltrated films, giving relative pore volumes of 0.265 and 0.540 for $\mathrm{T}_{3: 1}$ and $\mathrm{T}_{1: 2}$, respectively. 